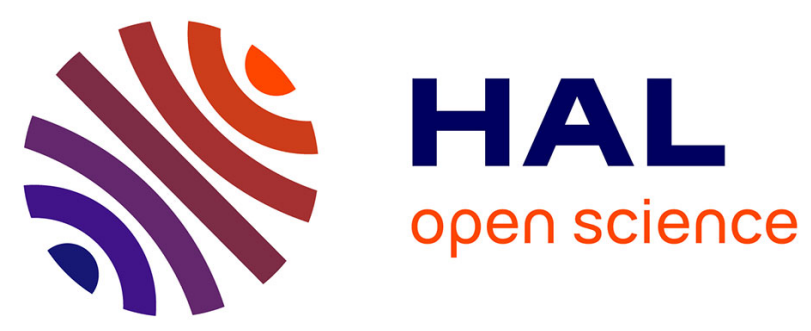

\title{
H-3 Measurement in Radioactive Wastes: Efficiency of the Pyrolysis Method to Extract Tritium from Aqueous Effluent, Oil, and Concrete
}

\author{
S. Guégan, R. Brennetot, M. Giuliani, S. Guegan, P. Fichet, L. Chiri, P. \\ Deloffre, A. Masset, C. Mougel, F. Bachelet
}

\section{To cite this version:}

S. Guégan, R. Brennetot, M. Giuliani, S. Guegan, P. Fichet, et al.. H-3 Measurement in Radioactive Wastes: Efficiency of the Pyrolysis Method to Extract Tritium from Aqueous Effluent, Oil, and Concrete. Fusion Science and Technology, 2017, 71 (3), pp.397-402. 10.1080/15361055.2017.1291242 . cea-02388596

\section{HAL Id: cea-02388596 https://hal-cea.archives-ouvertes.fr/cea-02388596}

Submitted on 19 Mar 2020

HAL is a multi-disciplinary open access archive for the deposit and dissemination of scientific research documents, whether they are published or not. The documents may come from teaching and research institutions in France or abroad, or from public or private research centers.
L'archive ouverte pluridisciplinaire HAL, est destinée au dépôt et à la diffusion de documents scientifiques de niveau recherche, publiés ou non, émanant des établissements d'enseignement et de recherche français ou étrangers, des laboratoires publics ou privés. 


\title{
H-3 measurement in radioactive wastes: Efficiency of the pyrolysis method to extract tritium from aqueous effluent, oil and concrete.
}

\author{
R. Brennetot ${ }^{1}$, M. Giuliani ${ }^{1}$, S. Guégan ${ }^{1}$, P. Fichet ${ }^{1}$, L. Chiri ${ }^{2}$, P. Deloffre ${ }^{1}$, A. Masset ${ }^{1}$, C. Mougel ${ }^{1}$, \\ F. Bachelet ${ }^{2}$ \\ ${ }^{1}$ CEA/DEN/DANS/DPC/SEARS/LASE, CEA Saclay, Bat 459 PC 171, 91191 Gif sur Yvette, France. \\ rene.brennetot@cea.fr \\ ${ }^{2}$ CEA Valduc, 21120 Is Sur Tille, France \\ franck.bachelet@cea.fr
}

Tritium measurement in nuclear waste is a key to determine the type of repository. This paper describes the methodology used to validate tritium measurement in various matrices using pyrolysis method with a new instrument available in the market. The efficiency obtained for tritium recovery in aqueous matrix, oil and concrete are respectively higher than 95\%, 93\% and $85 \%$.

\section{Introduction}

Due to its labile and chemical behavior (organic or inorganic forms), tritium is one of the most difficult radionuclide to measure. However for Decommissioning \&Dismantling (D\&D) projects concerning tritium facilities, stakeholder considers its characterization as a priority.

Liquid Scintillation Counting (LSC) is the reference method for tritium measurement. In the case of solid samples usually found in D\&D project, the pyrolysis method is generally used prior to measurement in order to isolate tritium from the matrix and to separate it from potential interfering species such as C-14 or S-35, Ref. 1-5. As Certified Reference Materials (CRM) are rather scarce for nuclear waste materials, our analysis have been validated through proficiency tests (Ref. 6) and with homemade materials (concrete, oil). For each matrix investigated, we tried to determine the recovery yields of tritium after pyrolysis. We will present results 
concerning optimization of the temperature programs to obtain the best extraction of tritium from the tested liquid matrix (liquid wastes, oil and aqueous effluents) and solid wastes (concrete). For optimizations, we also used the available CRMs proficiency tests for aqueous samples and intercomparison between laboratories for oil. For concrete, a specific study has been undertaken in order to study the influences of granulometry and sample quantity analyzed, on the recovery of $\mathrm{H}-3$ after pyrolysis.

\section{Experimental set-up}

The furnace built possesses (Fig 1) two independent heating zones. The first, where the sample is placed, can be setup (temperature gradient) whereas the second heating zone is maintained at $950^{\circ} \mathrm{C}$. Overall instrument dimensions are 1000 x 600 x $430 \mathrm{~mm}$ (w d h). Heating zones for each part are respectively $120 \mathrm{~mm}$ and $200 \mathrm{~mm}$ long respectively for programmable zone and constant zone. Temperature gradient can be useful for tritium speciation or tritium desorption in different matrices as shown in Ref 2. In addition, depending of the matrix where tritium has to be measured, the maximum temperature to reach for complete release of the tritium can be different from a matrix to another one. The sample in the first zone is swept by a nitrogen stream during the heat-up, while the second zone had a stream of $\mathrm{N}_{2}$ plus $\mathrm{O}_{2}$, in order to guarantee complete oxidation of the gases released during the pyrolysis taking place in the first zone. The sample (liquid or solid) is placed into the cold furnace in a combustion boat after a precise weighing. As the temperature rises, the gases obtained goes through a bubbler filled up with $\mathrm{HCl} 0.1 \mathrm{M}$ to trap $\mathrm{H}-3$. The bubbler is systematically cooled at temperature lower than $4^{\circ} \mathrm{C}$ for a better trapping efficiency. Difference between $\mathrm{H}-3$ trapping at room temperature and a temperature below $4^{\circ} \mathrm{C}$ could be up to $15 \%$. 


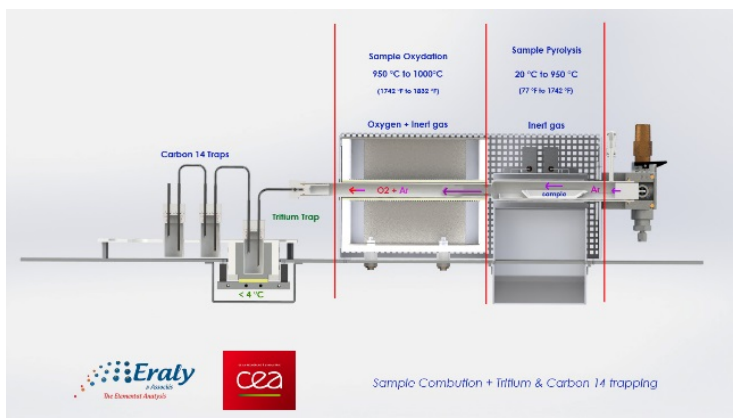

Fig. 1 : Schematic view of the pyrolyser designed by ERALY and Associates

Liquid samples are deposited on a small ceramic rod (cordierite material, porosity > 20\%) before pyrolysis. This ceramic is placed in the combustion boat, Fig.2.

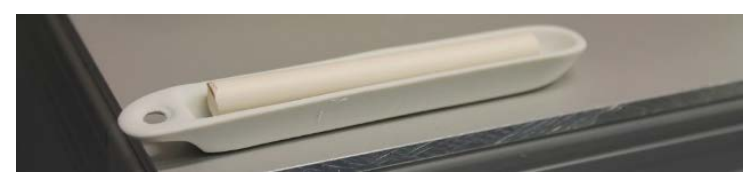

Fig. 2: Porcelain combustion boat with cordierite as sample support

H-3 used for recovery experiments and optimization was certified $\mathrm{H}-3$ labelled glucose (CERCA LEA, France). Tritiated oils were prepared by another CEA group (CEA valduc), and tritiated concrete was prepared with a known amount of certified $\mathrm{H}-3$ glucose in water mixed manually with cement and dried for at least 3 weeks at room temperature (Fig. 3). H-3 activity ranges for concrete spread from 50 to $1000 \mathrm{~Bq} / \mathrm{g}$. Possible radiolytical conversion of tritiated glucose to HTO was not evaluated but with the recovery of $\mathrm{H}-3$ observed, we can suppose that no conversion occurred.

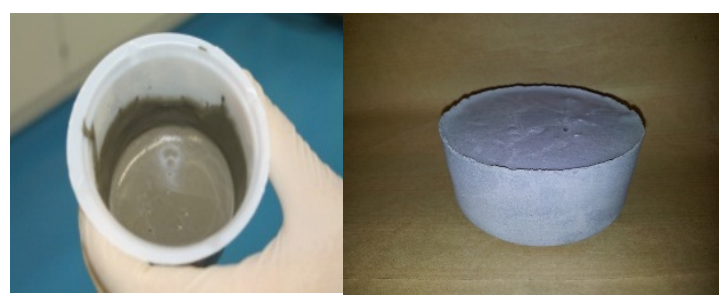

Fig. 3: Tritiated concrete before and after 3 weeks drying. 
Tritiated concrete was grinded and sieved to obtain powders with 4 different particle sizes: $\varnothing<250 \mu \mathrm{m}, 250 \mu \mathrm{m}<\varnothing<500 \mu \mathrm{m}, 500 \mu \mathrm{m}<\varnothing<1 \mathrm{~mm}$ and $\varnothing>1 \mathrm{~mm}$. The powder was directly deposited in the porcelain boat before pyrolysis.

After the pyrolysis, tritium activity was measured by Liquid Scintillation Counter (LSC, TriCarb 2910Tr, Perkin Elmer). The $5 \mathrm{ml}$ bubbler solution was mixed with $10 \mathrm{ml}$ of scintillation cocktail (Ultima Gold LLT, Perkin Elmer). LSC counter was calibrated with a certified standard liquid source (CERCA LEA, France). The counting time is 600 seconds.

After each sample pyrolysis, a pyrolysis blank is systematically carried out without porcelain boat using the same temperature program as used for sample.

\section{Results and discussion}

We have optimized temperature program and gas flows for each matrix. Specifically for the concrete matrix we have studied the effect of parameters such as the total powder quantity in the porcelain boat and the particles size.

\section{III.1 Validation on aqueous matrix}

For aqueous matrix, the $\mathrm{H}-3$ labelled glucose is diluted in water to obtain an activity around $40 \mathrm{~Bq} / \mathrm{g}$. To optimize the temperature program in order to obtain the best recovery of tritium, $0,4 \mathrm{ml}$ of this solution is deposited on the cordierite in the porcelain boat. The observation of a low influence of the gas flow rate led us to set it at $8.5 \mathrm{ml} / \mathrm{min}$ for both gases : inert gas in the first temperature programmable part of the oven and $\mathrm{O}_{2}$ in the oven part fixed at $950^{\circ} \mathrm{C}$ to 
oxidize the released gases. The optimized temperature program obtained from different experiences is shown in Fig. 4 . We can see 3 distinct stages, $350^{\circ} \mathrm{C}, 550^{\circ} \mathrm{C}$ and finally $950^{\circ} \mathrm{C}$. In the final part of the program, an inversion between inert gas and $\mathrm{O}_{2}$ is proceeded to be sure that the entire sample has been oxidized.

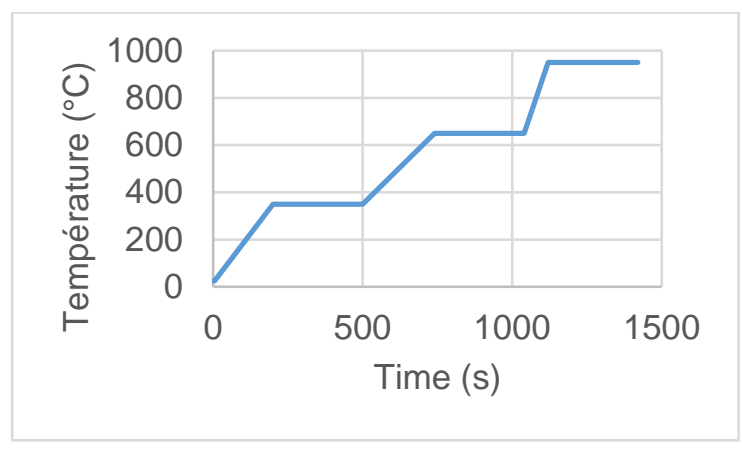

Fig. 4 : Temperature program for aqueous liquid pyrolysis.

With this pyrolysis program, a yield better than 95\% with a RSD of $4 \%$ for 10 replicates has been measured for $\mathrm{H}-3$.

\section{2 Validation on oil matrix}

Different temperature programs have been tested for the measurement of $\mathrm{H}-3$ in oil after pyrolysis. To prevent the formation of soot, no oxygen is added in the sample part of the oven which is always under inert gas flow. The different temperature programs tested are presented in Fig 5. For each experiment, $0.1 \mathrm{ml}$ of oil is used for direct measurement and quantity between 0.1 and $0.5 \mathrm{ml}$ of oil for pyrolysis. Oil used is colorless, so no color quench was observed for direct measurement by LSC. 


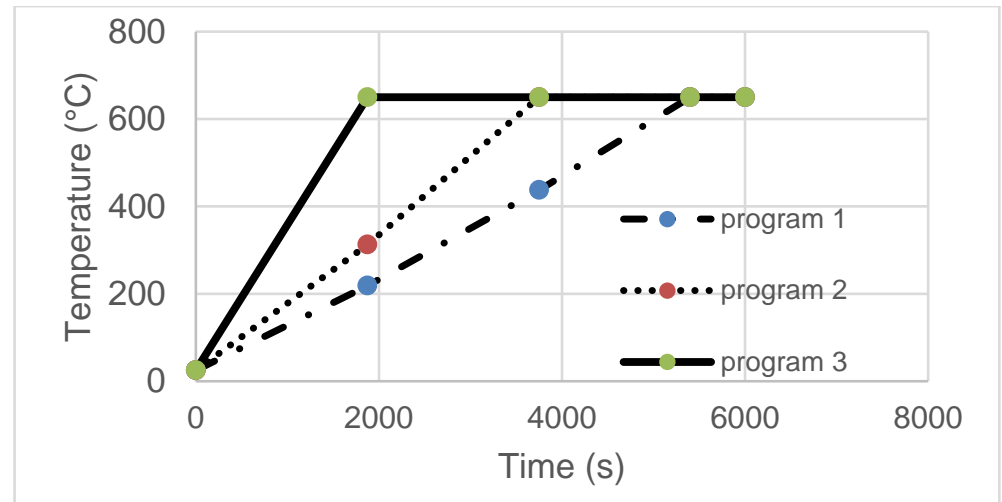

Fig. 5 : Temperature programs tested for $\mathrm{H}-3$ in oil matrix

H-3 yields obtained for each program were respectively of $94 \%, 45 \%$ and $25 \%$. These recoveries are the mean obtained from 2 pyrolysis realized on the lowest and highest $\mathrm{H}-3$ activities in oil (respectively $50 \mathrm{~Bq} / \mathrm{g}$ and $5000 \mathrm{~Bq} / \mathrm{g}$ ). Independently of the obtained recovery, a big scattering is observed between the values corresponding to the two levels of activity for program 2 and 3 (> $50 \%$ ), however there is a good agreement for recovery obtained with program 1 for both level of activity ( $<2 \%)$. Therefore we chose to use systematically program 1 for the validation of H-3 yield in oil and obtained a value of 93\% with a RSD of $2 \%$ (10 independent pyrolysis).

\section{III.3 Validation on concrete matrix}

For concrete matrix, in order to optimize the temperature program and the gas flow rate to obtain the best recovery of tritium by comparison with calculation from concrete preparation, $50 \mathrm{mg}$ to $300 \mathrm{mg}$ with different powder grain sizes were deposited in the porcelain boat (Fig. $6)$. 


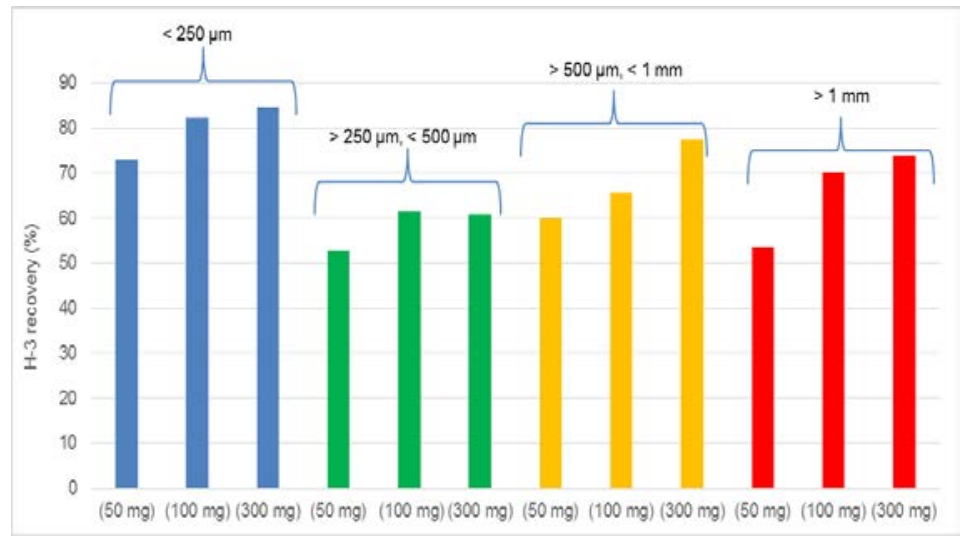

Fig. 6 : Influence of the particle size on H-3 recovery, preliminary tests.

The best experimental conditions are obtained with the same temperature program and gas flow rate as for aqueous liquid matrix pyrolysis. The best recovery is obtained for the smallest particles size, i.e. a diameter of less than $250 \mu \mathrm{m}$. If we have sample with high particles size, we use a step of grinding to obtain the optimum size $(<250 \mu \mathrm{m})$. Therefore, it was decided to study the influence of the amount analyzed in the porcelain boat for the smallest size of particles (Fig. 7). No specific experiment has been made with total amount $>300 \mathrm{mg}$ because with that amount the porcelain boat is almost full.

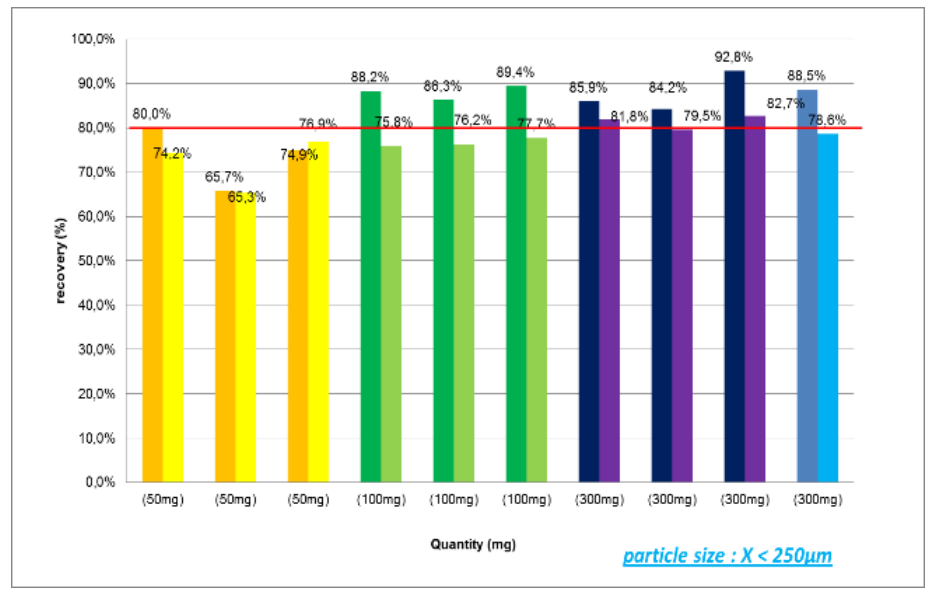

Fig. 7 : Influence of the total quantity analyzed by pyrolysis for the smallest particle size on $\mathrm{H}$ 3 recovery, preliminary tests. 
For each quantity, we made 2 experiments (one on each pyrolysis tube for $\mathrm{Bi}$ tube pyrolyzer), this is considered as preliminary results before validation and determination of yields of recovery for both $\mathrm{H}-3$ and C-14. We systematically obtained a H-3 recovery after pyrolysis better than $85 \%$ with a RSD of $4 \%$ for 10 pyrolysis for $<250 \mu \mathrm{m}$ and $\mathrm{m}=200 \mathrm{mg}$.

\section{Participation to inter-comparison Tests}

In 2015 our laboratory participated to an inter-comparison test organized by the Henri Becquerel National Laboratory (LNHB). Two aqueous solutions were distributed to all participants (> 30). The H-3 activity level was around 5 Bq/g and 40 kBq/g. Results obtained for both solutions are shown in Fig 8.
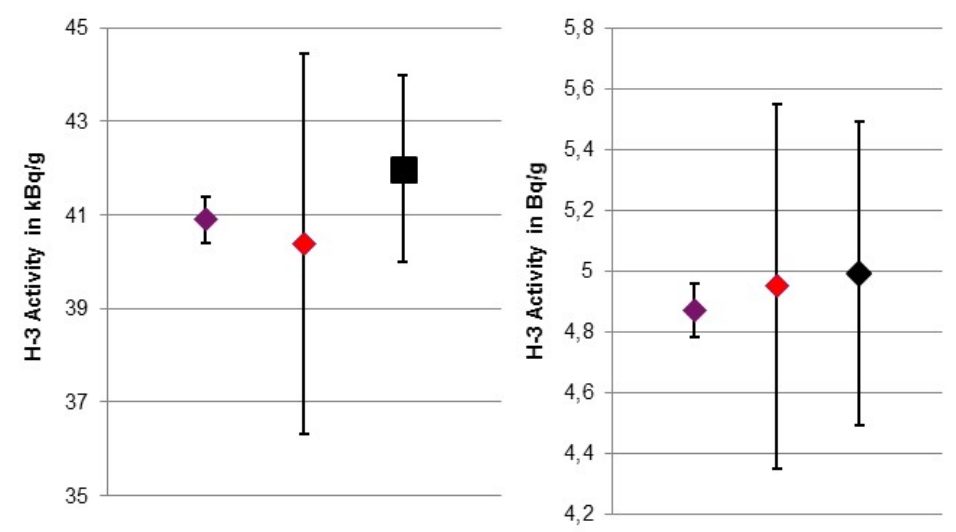

Fig 8 : Results for H-3 measurements in aqueous solution : first value is the reference value given by the LNHB, the second value in red is the result obtained by pyrolysis and the third result in black is the direct measurement by LSC for both level of H-3 activity, uncertainty reported are for $\mathrm{k}=2$ (95\% confidence level).

Results obtained on aqueous solutions for both activity values show a good agreement between pyrolysis and direct measurements. For both level of activity the difference is lower 
than $1.6 \%$ between the reference value and the value obtained by pyrolysis. Z-score is lower than 0.6 in both cases (respectively 0.5 and 0.3 ).

For oil matrix, no proficiency test is available so we decided to perform inter-comparison with the laboratory able to prepare tritiated oils and compare our measurements performed after pyrolysis with direct measurement of oil by LSC. Four different levels of activity have been tested from $20 \mathrm{~Bq} / \mathrm{g}$ to $5000 \mathrm{~Bq} / \mathrm{g}$. Results of these comparisons are presented in Fig 9.

There is a very good agreement between direct measurements and H-3 measurement after pyrolysis. Uncertainty obtained for pyrolysis measurement is higher than that obtained for direct measurement because it takes into account the yield of extraction determined by pyrolysis and its uncertainty. The laboratory which prepared the labelled oil obtained the same results with both techniques but different instruments.

For concrete matrix, we had the same problematic as for oil matrix as no proficiency test is available for this type of matrix. We decided to assess our results with an internal blind test by using a concrete prepared in our laboratory with unknown H-3 activity. We obtained with the optimized conditions of pyrolysis a difference of less than $5 \%$ between theoretical and measured $\mathrm{H}-3$ activity in that concrete.

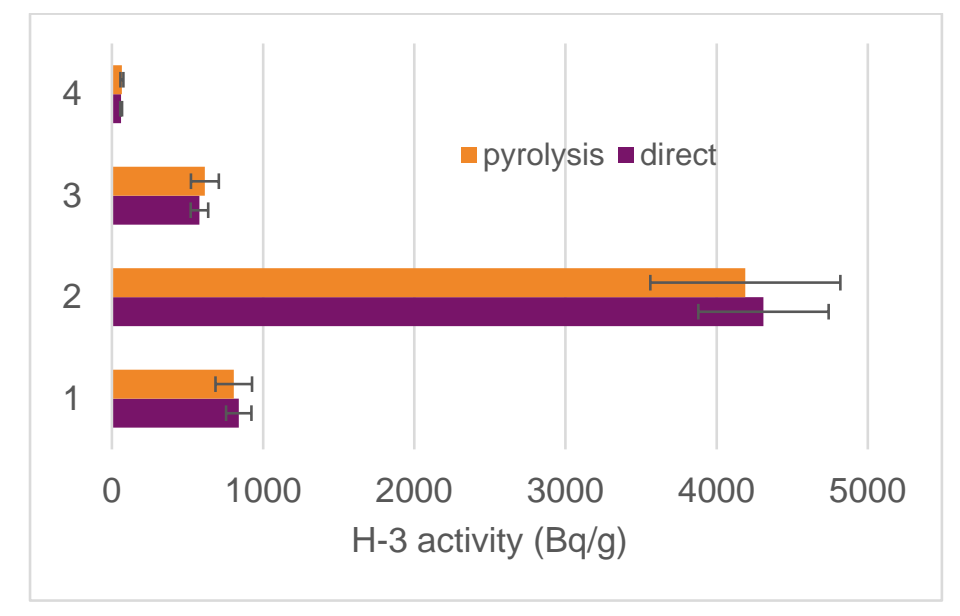

Fig. 9 : Comparison between H-3 direct measurement and H-3 after pyrolysis for 4 different levels of H-3 activity in oil. 


\section{Conclusion}

A new pyrolyser available on the market and designed by a small company, Eraly and Associates was tested to extract H-3 from different matrices representative of wastes that can be encountered in dismantling process. It differs from others pyrolyser on the market by the size and capability to extract effectively H-3 and C-14 from D\&D matrices. Up to 15 samples can be measured per day and compared to other furnace on the market, $\mathrm{H}-3$ and $\mathrm{C}-14$ is efficiently extract without need of catalyst in the oxidation zone. We optimized in terms of yields the operating conditions for 3 matrices : aqueous effluent, oil and concrete. We determined the best operating conditions for each matrix in order to obtain a $\mathrm{H}-3$ recovery better than $85 \%$ for all matrices. In order to evaluate the technique on aqueous effluents, we participated to proficiency test organized for pure water matrice and obtained very satisfactory results. Program is going on with other matrices such as rubber and graphite.

\section{ACKNOWLEDGMENTS}

We would like to thank ERALY and Associates company for their instrument and help to optimize pyrolysis conditions.

\section{REFERENCES}

1. J. S. OH et. Al.; J. Radioanal. Nucl. Chem. 299187 (2014)

2. P. E. WARWICK et. Al.; Anal. Chim. Acta. 676, 93 (2010)

3. Y. TORIKAI et al., Fusion and Science Technology, 41, 736, (2002)

4. H. R. Kim et al., Annals of Nuclear Energy, 38, 1074, (2011).

5. C. FRECHOU et al., J. Radioanal. Nucl. Chem. 273677 (2007). 
6. N. BAGLAN et al., Fusion and Science Technology, 67, 250, (2015) 